\title{
Biomimetics a New Paradigm for Surface Electrochemistry
}

\section{Jacek Lipkowski}

Surface Electrochemistry is now a wellestablished field that employs numerous spectroscopic, diffraction and imaging techniques to provide molecular level description to phenomena taking place at the metal-solution interface. Surface electrochemistry played a pivotal role in the development of electrocatalysis and electrodeposition. The golden age of surface electrochemistry were the eighties and the nineties of the last century when new in situ techniques such as infrared reflection absorption spectroscopy (IRRAS) surface enhanced Raman spectroscopy, surface X-ray scattering, electrochemical scanning tunnelling spectroscopy (STM) and atomic force microscopy (AFM) were introduced to electrochemical research. Symposia and sessions devoted to Surface Electrochemistry were then very well attended. The audiences followed with excitement new emerging opportunities to see individual atoms and molecules, to observe potential induced changes to the surface structure and to identify intermediates and products of electrode reactions using infrared or Raman spectra. Attending several recent meetings, I noticed that the excitement has vanished. Surface
Electrochemistry sessions have had small audiences relative to sessions on photoelectrochemistry, electrochemistry of materials, batteries or fuel cells as if surface electrochemistry was losing momentum or as if electrochemists are satisfied with the tools that they have at their disposal and are no longer interested in the further development of these tools.

However, there are several new research opportunities for surface electrochemistry and new fields where it can make a significant impact. One of them is biomimetics. Biomimetics is defined as "the study of the structure and function of biological systems as models for the design and engineering of materials and machines." Bilayer lipid membranes (BLMs) are popular models for mimicking biological membranes. BLMs are assembled from phospholipids which are amphiphilic molecules possessing a hydrophobic, hydrocarbon tail and a hydrophilic, polar headgroup region. Such supported bilayer membranes (s-BLMs) can be formed at surfaces of a variety of materials including glass, silicon, silicon nitride, quartz or mica using either a combination of Langmuir-Blodgett and Langmuir-Schaffer 
(LB-LS) deposition or vesicle fusion [1,2]. Lipid bilayers can also be tethered via functionalization to a gold surface. s-BLMs may also be directly deposited (formed by either the vesicle fusion or LB-LS methods) onto an electrode to study the effect of the static electric field on the membrane structure and stability $[3,4]$. Natural biological membranes are frequently exposed to static electric fields on the order of $10^{7}-10^{8} \mathrm{~V} \mathrm{~m}^{-1}$ [5]. The effect of the electric field on the membrane structure can be conveniently investigated using bilayers supported at a gold electrode surface, a metal which is chemically inert and behaves as an ideal capacitor over a large potential range [4].

Model biomimetic membranes deposited at a gold electrode surface allow transduction of chemical changes taking place in the membrane to electrical signal such as current or changes of the membrane capacitance and resistance. The transduction of chemical to electrical information allows for development of biosensors with potential applications for fast drug screening and selective detection of ions and molecules in general [6-8]. Such architecture also provides unique opportunity to study the membrane structure with many surface electrochemistry tools such as surface plasmon resonance (SPR) [6,8], infrared reflection absorption spectroscopy (IRRAS) [7-15] neutron reflectivity (NR) [16], STM [17,18] and AFM [19]. Biomimetics an emerging and largely unexplored field provides multiple new research opportunities for surface electrochemistry.

\section{References}

[1] E. Sackmann, Science, 271 (1996) 43.

[2] M.Tanaka, E. Sackmann, Nature, 437 (2005) 656.

[3] R. Guidelli, L. Beccuci,"Model Lipid Bilayers at Electrode Eurfaces", Chapter 4 in R. Alkire, D. M. Kolb and J. Lipkowski, Eds., "Bioelectrochemistry“, Wiley-VCH, New York, 2011.

[4] J. Lipkowski, Phys. Chem. Chem. Phys., 12 (2010) 13874.

[5] T. Y. Tsong, R. D. Astumian, Annu. Rev. Physiol., 50 (1988) 273.

[6] W. Knoll, I. Köper, R. Naumann, E.-K. Sinner, Electrochim. Acta, 53 (2008) 6680.

[7] Z. Coldrick, P. Steenson, P. Millner, M. Davies, A. Nelson, Electrochim. Acta, 54 (2009) 4954.

[8] E.-K.Sinner, S. Ritz, Y. Wang, J. Dostálek, U. Jonas, W. Knoll, Materials Today, 13 (2010) 46.

[9] S. L. Horswell, V. Zamlynny, H.-Q. Li, A.

R. Merrill, J. Lipkowski, Faraday

Discussions, 121 (2002) 405.

[10] I. Zawisza, A. Lachenwitzer, V. Zamlynny, S. L. Horswell, J. D. Goddard, J. Lipkowski, Biophys. J., 85 (2003) 4055.

[11] X. Bin, I. Zawisza, J. D. Goddard, J. Lipkowski, Langmuir, 21 (2005) 330. 
[12] N. Garcia-Araez, C. L. Brosseau, P. Rodriguez, J. Lipkowski, Langmuir, 22 (2006)10365.

[13] D. Matyszewska, J. Leitch, R. Bilewicz, J. Lipkowski, Langmuir, 24 (2008)7408.

[14] J. Leitch, J. Kunze, J. D. Goddard, A. L, Schwan, R. J. Faragher, R. Naumann, W. Knoll, J. R. Dutcher, J. Lipkowski, Langmuir, 25 (2009)10354.

[15] M. Roeefzaad, T. Klüner, I. Brand, Phys. Chem. Chem. Phys.,11 (2009)10140.
[16] I. Burgess, M. Li, S. Horswell, G. Szymanski, J. Lipkowski, J. Majewski, S. Satija, Biophys. J, 86 (2004) 1763.

[17] S. Xu, G. Szymanski, J. Lipkowski, J. Am. Chem. Soc., 126 (2004)12276.

[18] S. Sek, S. Xu, M. Chen, G. Szymanski, J. Lipkowski, J. Am. Chem. Soc., 130 (2008) 5736.

[19] M. Chen, M. Li, C. L. Brosseau, J. Lipkowski, Langmuir, 25 (2009)1028.

$$
\text { (ヤチェック・リプコウスキー、ゲルフ大、カナダ) }
$$

